\title{
THE INTERCULTURAL COMPETENCE OF MILITARY STUDENTS IN THE CONTEXT OF INTERNATIONAL MOBILITY
}

\author{
Florentina-Lavinia MATEI \\ University of Bucharest, Romania \\ mateilavinia92@yahoo.com
}

\begin{abstract}
This study aims to evaluate intercultural competence for military students before they go on an international mobility stage and after its completion, in order to see if intercultural competence is formed in real intercultural contexts. In the study, we addressed both theoretical and practical aspects of intercultural competence. As an instrument for data collection, an intercultural competency assessment questionnaire was used and, following its application, it was found that the high level of the "knowledge" component of intercultural competence determines a higher level of the other two elements -"attitudes" and "skills".
\end{abstract}

KEYWORDS: intercultural competence, knowledge-skills-attitudes, military field, international mobility stage, students

\section{Introduction}

Intercultural competence can be seen as a response to the intercultural challenges that take place during an intercultural mobility stage. It becomes a key competence, a way to empathize with people from another culture, to know the symbols, norms, values and characteristics of other cultures with which students come into contact during the international mobility stage.

Intercultural competence has come to the attention of researchers around the 1960 s, when much of the literature began writing about this competence. Rachel D. DuBois, an author who approached intercultural competence during this period, helped cultivate understanding between cultural groups by setting up intercultural programs (Deardorff \& Arasaratnam-Smith, 2017). Since 1990, studies on intercultural competence have continued to develop through the publication of several theories.
The impetus for research continued with contributions from several researchers from various disciplines: Darla K. Deardorff, 2006, Fantini, 2006, Spitzberg \& Changnon, 2009.

Due to the manifestation of cultural diversity in an inevitable way, intercultural competence becomes more and more appreciated, representing "the ability of people to relate and the ability to adapt to very different cultural and ethnic environments" (Lustin, 2005 apud. Spitzberg, Changnon, 2009, p. 4).

Fantini (2006) defined intercultural competence as a complex of skills necessary to perform effectively and appropriately in interaction with others who are linguistically and culturally different from oneself.

Another conception of the concept of intercultural competence is found in the Romanian specialized literature. Nedelcu defined intercultural competence as 
"a multitude of specific intercultural beliefs and behaviours that advocates openness, empathy and communication for the understanding and capitalization of the logic of each culture, close or remote, for the perception and observance of alterity in all its differentiating elements" (Nedelcu, 2008, p. 25).

In the paper Developing intercultural understanding and skills: models and approaches (Perry \& Southwell, 2011), the authors present some approaches to intercultural competence. Bennet (2008) points out the similarities between the definitions, mentioning that most theorists agree that intercultural competence includes a set of cognitive skills, emotional and behavioural skills and characteristics that effectively and appropriately support interaction in a variety of cultural contexts. In the same paper, Hiller and Wozniak (2009) associate intercultural competence with tolerance to ambiguity, behavioural flexibility, communication awareness, discovery of knowledge, respect for others and empathy (Bennet, 2008 apud. Perry \& Southwell, 2011).

Also in 2009, intercultural competence was, in the view of authors Spitzberg and Changnon, an adequate and effective management of the interaction between people who have cognitive, affective and behavioural characteristics different from people in another culture (Spitzberg \& Changnon, 2009 apud. Deardorff \& Arasaratnam-Smith, 2017).
In the paper Developing intercultural competences. Guide for Romanian soldiers participating in missions outside the territory of the Romanian State, by Vasile Marinescu (2015), a definition given to the concept of intercultural competence belongs to the authors Abbe, Gulick, Herman (2007), Abbe, Gallus (2012), according to which it represents "a set of behaviours and attitudes that, once acquired, allow us to act effectively in different contexts and situations from a cultural standpoint" (Marinescu, 2015, p. 10).

Being among the theorists who have approached the concept of intercultural competence, Deardorff argues that it is made up of three main components: knowledge, attitudes, skills. Deardorff (2006) describes what each component of intercultural competence means.

Knowledge is the first essential component in the process of acquiring intercultural competence and includes: awareness of one's own culture; knowledge specific to culture; sociolinguistic awareness; understanding of global issues and trends.

Attitudes are the second component in the development process of intercultural competence, including: respect; opening; curiosity and discovery.

Skills represent the third component in the process of developing intercultural competence including: listening, observing, evaluating; analysis, interpretation and reporting; critical thinking (Deardorff, 2006).

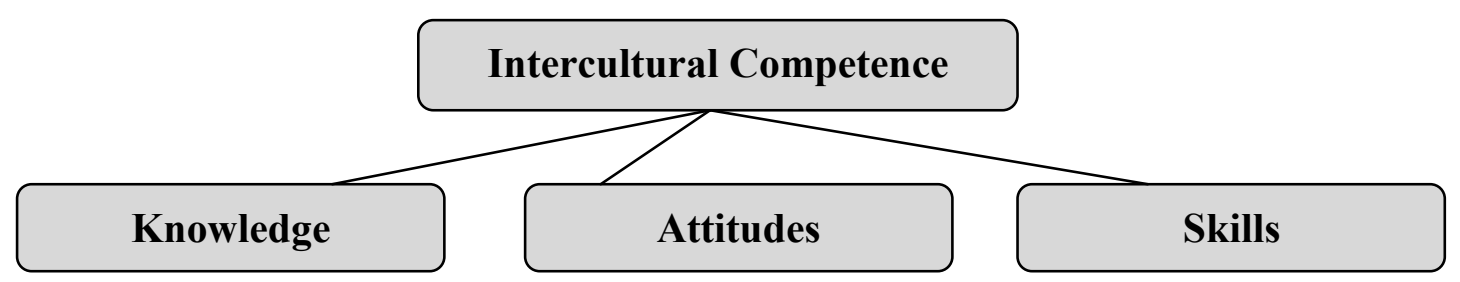

Figure no. 1: The components of Intercultural Competence

(Source: Deardorff \& Arasaratnam-Smith, 2017) 
Following the approaches of theoreticians in the field, we can conclude that intercultural competence is a set of knowledge, attitudes and skills needed by a person in an intercultural context to recognize and respect differences, to relate to people from different cultures, and to mitigate the risk of cultural shock that could affect integration into the host culture.

\section{Research Methodology}

\subsection{Objectives and Hypotheses of the Research}

Taking into consideration the information in the above mentioned literature, this study aimed to achieve the following objectives:

O1. Investigating the statistically significant linear relationship between the knowledge and attitudes of military students who will go on an international mobility stage;

O2. Investigating the statistically significant linear relationship between the knowledge and skills of military students who will go on an international mobility stage;

O3. Investigating the statistically significant linear relationship between the skills and attitudes of military students who will go on an international mobility stage.

In order to achieve the above objectives, the following hypotheses were proposed:

$\mathbf{I}_{1}$ It is assumed that there is a statistically significant positive relationship between the knowledge of intercultural competence and the skills of military students going on an international mobility stage.

$\mathbf{I}_{2}$ It is assumed that there is a statistically significant positive relationship between the attitudes and knowledge about the intercultural competency of military students going on an international mobility stage.

$\mathbf{I}_{3}$ It is assumed that there is a statistically significant positive relationship between the attitudes and skills of military students going on an international mobility stage.

\subsection{Sample of Research}

The study was attended by 45 students from the "Nicolae Bălcescu" Land Forces Academy in Sibiu, 31 males and 14 females aged 19-27 $(\mathrm{m}=21.44, \mathrm{SD}=4.54)$ (Table no. 2), who will go on an international mobility stage through an Erasmus Plus mobility program during March, April and May, 2019. The participants were given the questionnaire, they expressed their consent to participate in the research by filling it out, and they were informed that the data obtained are confidential and anonymous, used only for scientific purposes, in accordance with EU Regulation 679/2016 on the protection of natural persons with regard to the processing of personal data.

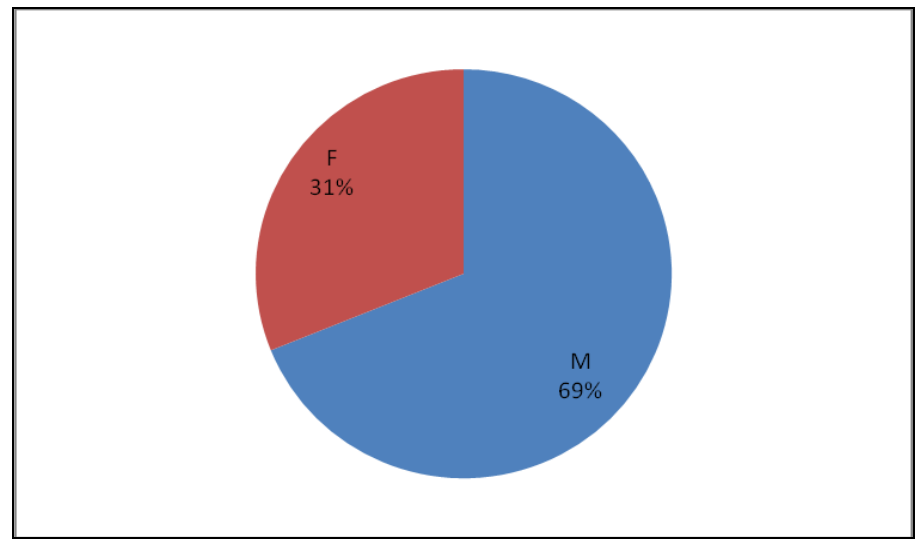

Figure no. 2: Distribution of participants by gender 


\subsection{Method and Research Tool}

The survey method based on a questionnaire is one of the most used methods, and the data is collected using the questionnaire.

In order to investigate the study hypotheses, the Intercultural Competence Assessment Questionnaire research tool was designed and used, its aim being to evaluate the intercultural competency of the Romanian military students who will go on an international mobility stage.

The Intercultural Competence Assessment Questionnaire was developed on the basis of the Intercultural Competence Assessment Questionnaire of the EIL Federation Research Project (2005). The questionnaire includes 28 items, which are organized according to the three components of intercultural competence: knowledge, attitudes, skills. Each item of this questionnaire is evaluated on a fivestep Likert scale: strongly agree, agree, neutral, disagree, strongly disagree.

For each subscale of the questionnaire, the Cronbach alpha coefficient was calculated to obtain an internal consistency index of:

- 0.75 for Knowledge Subscale (Table no. 1);

- 0.91 for Attitudes Subscale (Table no. 1);

- 0.91 for Skills Subscale (Table no. 1), which means that the items correlate strongly with the scale for the sample of this research.

Table no. 1 Alpha Cronbach Coefficient

Cronbach Alpha for the Intercultural Competence
Assessment Questionnaire

\section{Results}

The conducted study is a longitudinal, pre-test/post-test type study.

The Intercultural Competence Assessment Questionnaire was applied to students before leaving for the international mobility stage, and the study shows the results of the initial assessment (pre-test) phase. After completing the stage, the final assessment (post-test) phase follows, and the questionnaire will be applied once again in order to assess, by identifying the differences between the two assessments, whether the intercultural competence was formed/developed during the stage.
For the statistical analysis of the study data, non-parametric and parametric tests were applied. The Kolmogorov-Smirnov test was applied to normality testing, and the Pearson test was applied for testing assumptions and correlations between the components of intercultural competence (knowledge, attitudes, skills).

In Table no. 2 the descriptive statistics of the values of the research variables can be observed. Thus, for the knowledge variable, the average is 20.42 , the minimum value is 15 and the maximum value is 28 . 
The attitudes variable has the values average of 32.93 , the minimum value is 23 , and the maximum value is 40 , while the values average of the skills variable is 41.24 , the minimum value is 28 , and the maximum value for this last variable is 50 .

Table no. 2

Descriptive Statistics

\begin{tabular}{cccccc}
\hline \multicolumn{5}{c}{ Descriptive statistics } \\
\hline & $\mathrm{N}$ & \multicolumn{2}{c}{ Minimum Maximum } & Mean & $\begin{array}{c}\text { Std. } \\
\text { Deviation }\end{array}$ \\
\hline Age & 45 & 19 & 27 & 21.44 & 1.546 \\
Knowledge & 45 & 15.00 & 28.00 & 20.4222 & 3.19438 \\
Attitudes & 45 & 23.00 & 40.00 & 32.9333 & 4.55970 \\
Skills & 45 & 28.00 & 50.00 & 41.2444 & 6.26373 \\
Valid N & 45 & & & & \\
(listwise) & & & & & \\
\hline
\end{tabular}

To achieve the objectives, hypotheses 1, 2 and 3 were tested.

As can be seen in the table below, all variables have a normal distribution of values, and the results of the KolmogorovSmirnov test are as follows:
- for the knowledge variable $Z=0,108$, $\mathrm{p}=0,200, \mathrm{p}>0,05$;

- for the attitudes variable $Z=0,111$, $\mathrm{p}=0,200, \mathrm{p}>0,05$;

- for the skills variable $\mathrm{Z}=0,110$, $\mathrm{p}=0,200, \mathrm{p}>0,05$.

Table no. 3

Kolmogorov-Smirnov Test

\begin{tabular}{|c|c|c|c|c|}
\hline \multicolumn{5}{|c|}{ One-Sample Kolmogorov-Smirnov Test } \\
\hline & & knowledge & attitudes & skills \\
\hline \multirow[t]{2}{*}{$\mathrm{N}$} & & 45 & 45 & 45 \\
\hline & Mean & 20,4222 & 32,9333 & 41,2444 \\
\hline Normal Parameters ${ }^{\mathrm{a}, \mathrm{b}}$ & $\begin{array}{c}\text { Std. } \\
\text { Deviation }\end{array}$ & 3,19438 & 4,55970 & 6,26373 \\
\hline \multirow{3}{*}{$\begin{array}{l}\text { Most Extreme } \\
\text { Differences }\end{array}$} & Absolute & 108 & 111 &, 110 \\
\hline & Positive & 108 & ,094 & 081 \\
\hline & Negative &,- 079 &,- 111 &,- 110 \\
\hline \multicolumn{2}{|c|}{$\begin{array}{c}\text { Test Statistic } \\
\text { Asymp. Sig. (2-tailed) }\end{array}$} & $\begin{array}{c}108 \\
, 200^{\mathrm{c}, \mathrm{d}}\end{array}$ & $\begin{array}{c}, 111 \\
, 200^{\mathrm{c}, \mathrm{d}}\end{array}$ & $\begin{array}{c}, 110 \\
, 200^{\mathrm{c}, \mathrm{d}}\end{array}$ \\
\hline
\end{tabular}

a. Test distribution is Normal.

b. Calculated from data.

c. Lilliefors Significance Correction.

d. This is a lower bound of the true significance.

Table no. 4 shows that Hypotesis 1, which assumes that there is a statistically significant positive relationship between the knowledge of intercultural competence and the attitudes of students going on an international mobility stage, is supported by statistical data $(\mathrm{r}=0,456, \mathrm{P}=0,0002$,
$\mathrm{P}<0,01)$. The effect size is $\mathrm{r}^{2}=0.2$, which shows a small value.

Hypothesis 2, which assumes that there is a statistically significant positive relationship between the skills and knowledge of the intercultural competence of students going on an international 
mobility stage, is also supported by the statistical data $(\mathrm{r}=0,459, \mathrm{p}=0,0002$, $\mathrm{p}<0,01)$. The effect size is $\mathrm{r}^{2}=0.2$, which shows a small value.

Table no. 4 also shows that Hypothesis 3, which assumes that there is a statistically significant positive relationship between the attitudes and the skills of students going on an international mobility stage is supported by statistical data $(\mathrm{r}=0,881, \mathrm{p}=0,0001, \mathrm{p}<0,01)$. The effect size is $r^{2}=0,77$, which shows a small value.

Table no. 4 Correlations

\begin{tabular}{|c|c|c|c|c|}
\hline \multicolumn{5}{|c|}{ Correlations } \\
\hline & & knowledge & attitudes & Skills \\
\hline \multirow{3}{*}{ Knowledge } & $\begin{array}{c}\text { Pearson } \\
\text { Correlation }\end{array}$ & 1 &, $456^{* *}$ &, $459^{* *}$ \\
\hline & Sig. (2-tailed) & & ,002 & ,002 \\
\hline & $\mathrm{N}$ & 45 & 45 & 45 \\
\hline \multirow{3}{*}{ attitudes } & $\begin{array}{c}\text { Pearson } \\
\text { Correlation }\end{array}$ &, $456^{* *}$ & 1 &, $881^{* *}$ \\
\hline & Sig. (2-tailed) &, 002 & &, 000 \\
\hline & $\mathrm{N}$ & 45 & 45 & 45 \\
\hline \multirow{3}{*}{ skills } & $\begin{array}{c}\text { Pearson } \\
\text { Correlation }\end{array}$ &, $459^{* *}$ &, $881^{* *}$ & 1 \\
\hline & Sig. (2-tailed) &, 002 &, 000 & \\
\hline & $\mathrm{N}$ & 45 & 45 & 45 \\
\hline
\end{tabular}

All the above information is also shown in Figures no. 3, Figure no. 4 and Figure no. 5. Thus, one can observe the following: the higher the values of a variable, the higher the other variables.
The higher the level of knowledge, the more attitudes and skills seen as components of intercultural competence have a higher level.

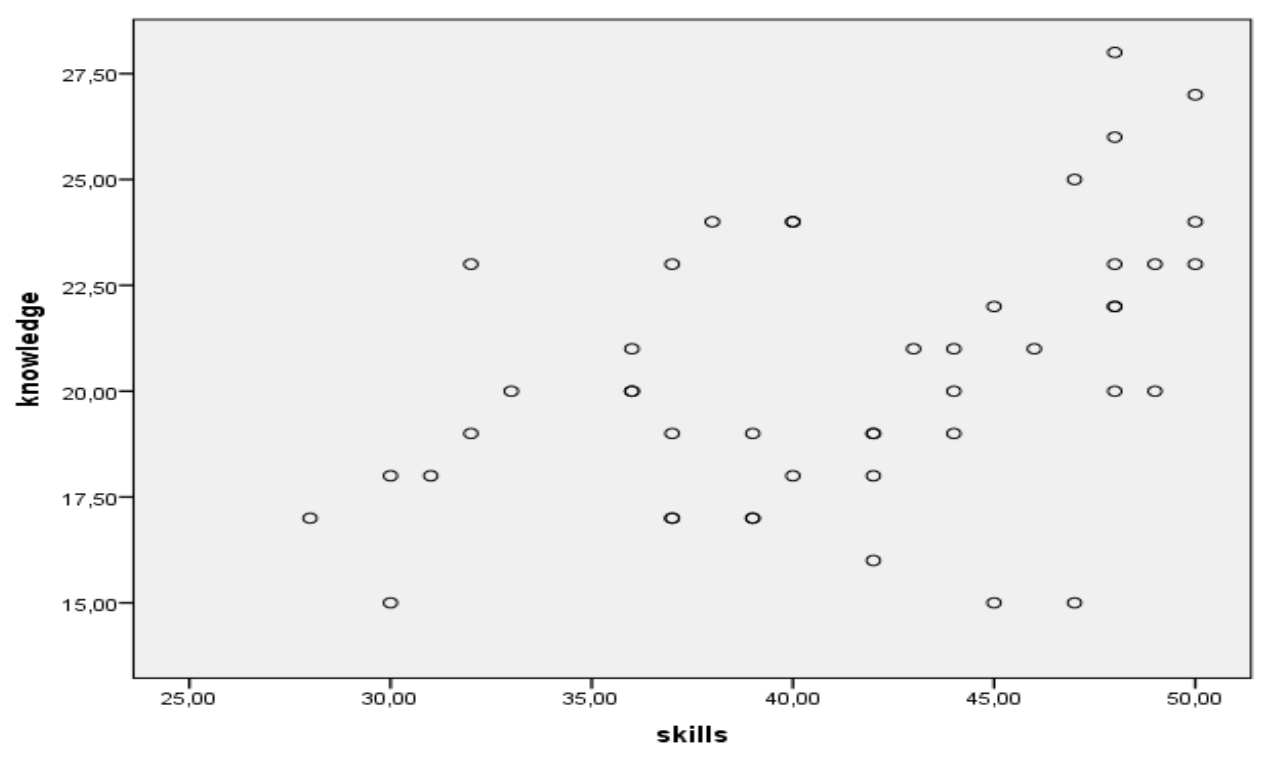

Figure no. 3: The linear relationship between knowledge and skills 


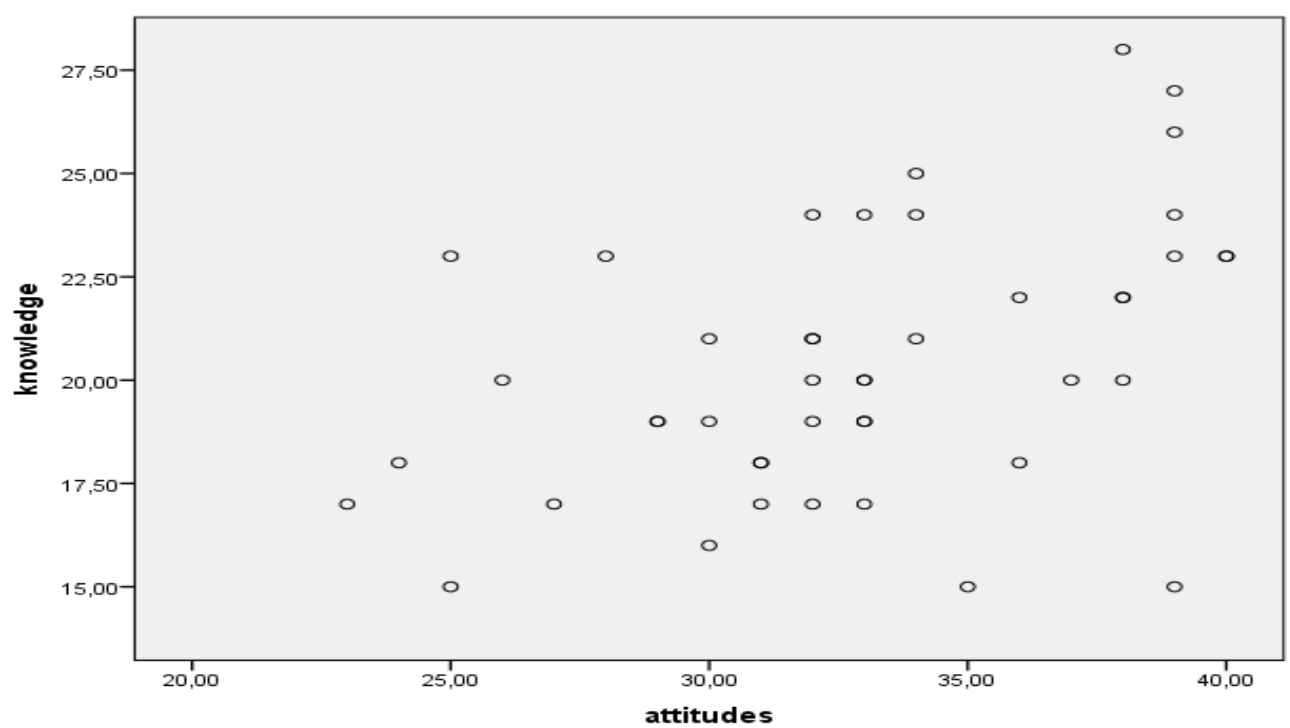

Figure no. 4: The linear relationship between knowledge and attitudes

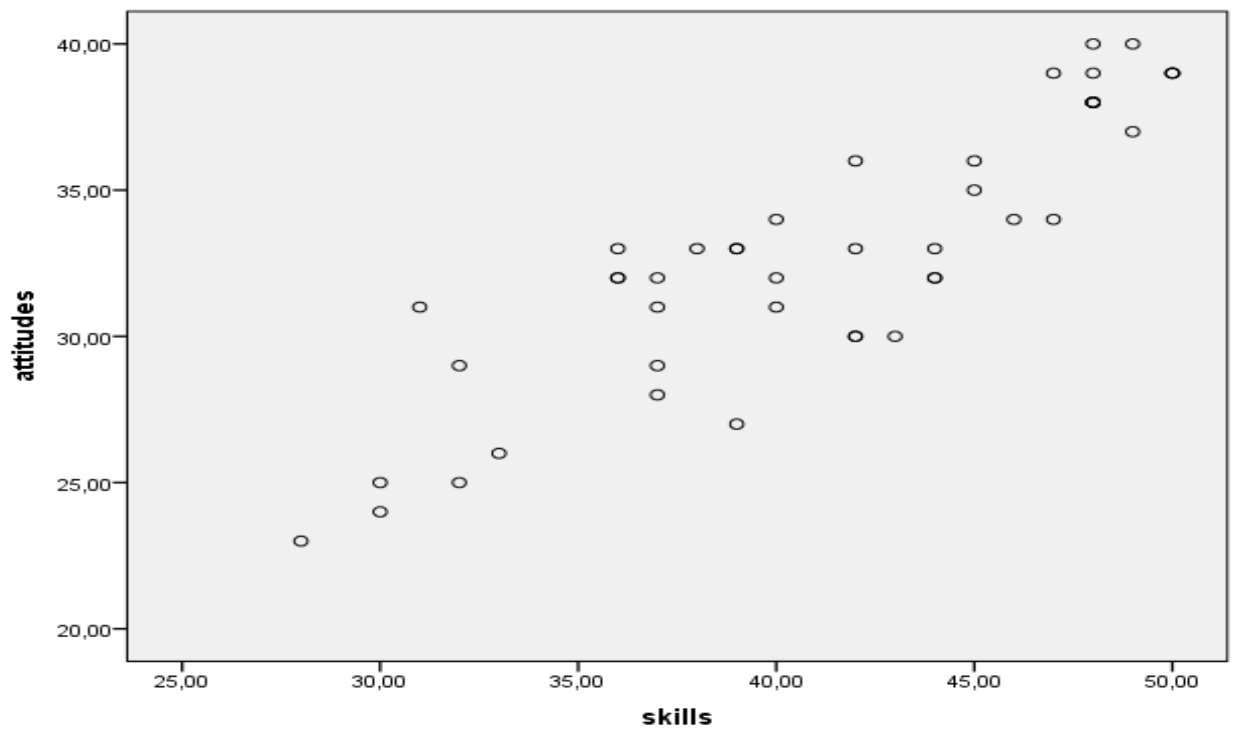

Figure no. 5: The linear relationship between attitudes and skills

\section{Discussions and Conclusions}

The results of the research demonstrate the following: the higher the level of knowledge, the higher the level of attitudes and skills. Thus, having knowledge of intercultural competence can positively influence the attitudes and skills of military students towards the host culture and its characteristics, adaptation of appropriate behaviour and the desire to develop intercultural competence during the international mobility stage.
One limit of this study is that the sample used (45 students) was satisfactory, but not enough to draw strong conclusions. In the future, we will conduct studies with larger and more diverse samples (different nationalities).

The results of this study belong to the initial assessment phase and are to be compared with the results of the final assessment phase, as the questionnaire is to be administered for the second time at the return of military students from the international mobility stage. 


\section{REFERENCES}

Deardorff, D. K. (2006). The Identification and Assessment of Intercultural Competence as a Student Outcome of Internalization at Institutions of Higher Education in the United States. Journal of Studies in International Education, Vol. 10, Issue 3, 241-266, available at: https://doi.org/10.1177/1028315306287002.

Deardorff, D. K., \& Arasaratnam-Smith, L. A. (2017). Intercultural Competence in Higher Education. International Approaches, Assessment and Application. 1st Edition, Routledge, available at: https://www.researchgate.net/publication/313388295 Intercultural Competence Development in Higher Education.

Fantini, A, \& Tirmizi, A. (2006). Exploring and assessing intercultural competence. World Learning Publications, available at: https://digitalcollections.sit.edu/cgi/ viewcontent.cgi? article $=1001 \&$ context $=$ worldlearning publications.

Hiller, G.G., \& Wozniak, M. (2009). Developing an intercultural competence programme at an international cross-border university. Intercultural Education, Vol. 20, Issue 4, 113-24.

Marinescu, V. (2015). Dezvoltarea Competențelor Interculturale. Ghid pentru militarii români participanți la misiuni în afara teritoriului Statului Român. București: Editura Centrului Tehnic - Editorial al Armatei.

Nedelcu, A. (2008). Fundamentele educației interculturale. Diversitate, minorităţi, echitate. Iași: Editura Polirom.

Perry, L.B., \& Southwell, L. (2011). Developing intercultural understanding and skills: models and approaches. Intercultural Education Journal, Vol. 22, Issue 6, 453-466, available at: https://www.tandfonline.com/doi/abs/10.1080/14675986.2011.644948.

Spitzberg, B. H., \& Changnon, H. (2009). Conceptualizing Intercultural Competence. In Deardorff, D.K., The Sage Handbook of Intercultural Competence. Thousand Oaks, California, USA: Sage Publications, 2-52, available at: https://www.researchgate.net/ publication/311457415_Book_Review_The_SAGE_Handbook_of_Intercultural_Competence by Deardorff D K Ed. 